\title{
Screening of Effective Markers for Mesophilic Bacterium Growth Using Factorial Experimental Design
}

\author{
Mani Malam Ahmad ${ }^{1 *}$, Abd. Aziz Mohd Azoddien ${ }^{1}$, Mior Ahmad Khusairi bin \\ Mohd Zahari ${ }^{1}$, Mazrul Nizam bin Abu Seman ${ }^{1}$ and Mohammed Saedi Jami ${ }^{2}$ \\ ${ }^{1}$ Faculty of Chemical and Natural Resources Engineering, Universiti Malaysia \\ Pahang (UMP), Lebuhraya Tun Razak, 26300 Gambang, Kuantan, Pahang, \\ Malaysia \\ ${ }^{2}$ Faculty of Engineering, Department of Biotechnology Engineering, International \\ Islamic University, Malaysia (IIUM), Gombak, 50728, Kuala Lumpur, \\ Malaysia \\ mmahmadu@gmail.com*,aaziz@ump.edu.my,ahmadkhusairi@ump.edu.my, \\ mazrul@ump.edu.my,saedi@iium.edu.my
}

\begin{abstract}
Attempts to gain an insight and present bacterial growth pattern from OVAT perspectives are quite defective and strenuous. The present study aimed at evaluating this concept from the different perspective by evaluating factors with more impacts on the growth of a mesophilic bacterium, Bacillus cereus (ATCC 14579) in a batch type medium of orbital shake flasks. Screening of linear and interactions effects of parametric markers was evaluated by two level $\left(2^{4}\right)$ factorial design of experiment (DOE). Growth was found to respond significantly to nutrient concentration coupled with other independent variables. The factorial models established from experimental design to investigate the individual and interactions effects toward the response within the selected variables of nutrient concentration (4-16 $\left.\mathrm{g} \mathrm{l} \mathrm{l}^{-1}\right)$, temperature $\left(30{ }^{\circ} \mathrm{C}-42{ }^{\circ} \mathrm{C}\right)$, agitation $(140 \mathrm{rpm}$-200 rpm) and acclimatization time (24 hours-72 hours). These were statistically validated using analysis of variance (ANOVA). The results revealed that the model terms were all significant with $F$-value of 251.07 at $(p=0.004)$. The model term having the most significant effect on the response was nutrient concentration. And the magnitude of the influence is in the ascending order $A>B>A B>C>A C$. Based on the $R^{2}$ and adjusted $R^{2}$ the estimated model terms spell high degree of relationship between observed and predicted values, thus the prediction ability of the models is maintained. It could, therefore, be concluded that nutrient concentration, temperature and acclimatization time were variables that greatly limit growth at a specific range.
\end{abstract}

Keywords: Screening, markers, mesophilic, bacterium, growth, factorial, design

\section{Introduction}

Bacterial adjustment to its immediate environment depends on a range of physical and chemical stimulants [1-3]. Changes in any of the growth influencing factors such as nutrient availability, temperature, $\mathrm{pH}$, aeration, redox potential, water activity, media concentration, and volume were reported to have an effect on bacterial growth rate, which is universally known as stress phenomenon [1]. B. cereus, as reported in some scriptures has the potential of withstanding a wide range of oxidative stress conditions through evolving a set of strategies that allow its growth and biosynthesis [4]. One of such strategy is the formation of stress-resistant endospores and as well uptake of external DNA, which allows the bacteria to adapt by recombination [4,6] (Dos Santos et al., 2013;

Corresponding author: Mani Malam Ahmad,

Faculty of Chemical and Natural Resources Engineering,

University Malaysia Pahang; +601136560301 
Zhong et al., 2014). Brake down of growth substrates involve a series of biochemical activities facilitated by integrated enzyme systems within the host bacterial cells ${ }^{[6,7]}$ (Swain et al. 2006; Abada 2014). Various research studies were conducted to ascertain the relative important of individual effects of these growth factors. However, not much is reported concerning the interaction and complementary effects of these factors influencing the bacterial growth using factorial experimental design in orbital shake flasks.

The conventional approach used for screening relation between independent (growth limiting factors) and dependent (growth) variables involves varying one variable at a time while fixing all other at certain level, is known as "one-variable-at-a-time (OVAT), or one-factor-at-a-time, (OFAT)" [3, 8,9,10](Singh et al. 2011; Navaneeth et al. 2009; Mosquera et al. 2014; Cook 1996). Although, this approach has been found to be useful in observing the individual effects of the media components and process conditions $[11,12]$ (Mandenius \& Brundin, 2008; Tabbene, et al., 2009), it is however, lacking in predicting the interaction and interrelationship between the various components influencing the realization of a particular response [5,9,11,12] (Cho, Kim, \& Kim, 2009; Curtis, 2011; Navaneeth et al., 2009; Tabbene, et al., 2009; Zhong et al., 2014). In addition, this approach has failed to fill the pipeline, as it is time-consuming by having too much number of experimental runs, as well as being full of bias. This is further argued by the fact that variable cannot be studied by varying one factor at a time, as it often does not allow determination of actual optimum level of different components for a particular metabolic activity, as well as enable identification of vital factors affecting a process [14] (Ridzuan, et al., 2016). Comparatively, statistical factorial design of experiments, provide an alternative approach through screening of a particular process by considering individual and mutual interactions among the variables and give an estimate of the combined effect of these variables on the final result [15] (Onsekizoglu, et al., 2010; Murthy et al. 2000; Mizumoto and Shoda, 2007; Pryor et al., 2007(b)). A factorial design is used to generate data for future response surface optimization studies, which facilitate determination of optimum conditions for any particular processes $[14,16]$ (Hooshyar et al., 2014; Ridzuan et al., 2016).

The relationship between the response and the input is given "Refer to Equ. 1"

$$
\eta=f\left(\mathrm{x}_{1}, \mathrm{x}_{2} \ldots . . \mathrm{xn}\right)+\varepsilon .
$$

Where $\eta$ is the response, $f$ is the unknown function of response, $\mathrm{x}_{1}, \mathrm{x}_{2} \ldots . \mathrm{xn}$ denote the independent variables, also called natural variables, $\mathrm{n}$ is the number of the independent variables and finally $\varepsilon$ is the statistical error that represents other sources of variability not accounted for by $f$. Selected independent variables are assign levels based on different ranges each of the coded variables is assigned to a range from -1 to +1 , so that they all affect the response more evenly, so the units of the parameters are insignificant. Generally, the polynomial model used a full quadratic equation, and is given "Refer to Equ. 2"

$$
Y=\beta 0+\Sigma \beta i x i+\Sigma \beta \text { iixi }^{2}+\Sigma \beta \text { ijxixj }
$$

Where $\mathrm{Y}$ is the predicted response, $\beta 0, \beta \mathrm{i}, \beta \mathrm{ii}$ and $\beta \mathrm{ij}$ are regression coefficients for intercept, linear, quadratic and interaction coefficients respectively and $\mathrm{xi}$ and $\mathrm{xj}$ are coded independent variables. The system of equations given above is solved using the method of least squares (MLS) of multiple regression techniques using Design expert software (Stat-Ease, Inc, version 7.1.6, Minneapolis, USA). Once the regression coefficients are obtained, the estimated response could be easily calculated using model equation.

Determination of actual bacterial growth pattern and the limiting factors involved is obviously erroneous and onerous, owing to the complexity of the mechanisms involved. This is quite apparent with the approach of using one-factor-at-a-time, due to its unjustifiable method of choosing factors and their ranges, besides being a time consuming and its inability to reveal interactions contribution of these factors toward bacterial growth 
and biosynthesis. Indeed, so much remain unknown regarding these mechanisms. Consequently modeling and simulative approach to understanding and predicting microbial growth pattern, as well as the nature of linear and interactions impact of growth influencing variables is found to be a prepared and best approach. The present study was envisaged with an aim to highlight a novel approach of applying factorial experimental statistical design to screen the individual and interactions effects of nutritional composition, acclimatization time and other physical parameters such as agitation speed, temperature, on the growth pattern in a shake flask. The outcomes of the screened factors influencing bacterial growth together with their optimum values could further be utilized to optimize the process conditions of this isolates in modeling optimum growth conditions.

\section{Materials and Methods}

\subsection{Strain and Cultivations}

This research was carried out with B. cereus (ATCC 14579) and its growth media obtained from Merck (Malaysia) Sdn. Bhd as a local agent dealing with the bacteria, sourced from Microbiologic, 217 Osseo Ave. North, St. Cloud, USA. Enriched culture media was prepared in accordance with the manufacturer's guidelines. Typically, $8 \mathrm{~g}$ of nutrient broth was dissolved de-ionized water (DI) to a final volume of $1 \mathrm{~L}$ in a Schott bottles and shaken vigorously until it dissolved. The solution was heated on a hot plate and sterilized in an autoclave $\mathrm{H}+\mathrm{P}$ Varioklav Steam Sterilizer ESCO, at $121{ }^{\circ} \mathrm{C}$ for 15 minutes; the sterilized media was then placed in a water bath to cool the media to $47^{\circ} \mathrm{C}$ before pouring into various $20 \mathrm{ml}$ sampling bottles. The stock cultures of B. cereus were maintained throughout the experiment by periodic sub-transfer at least fortnightly on nutrient agar (NA) and stored at $4{ }^{\circ} \mathrm{C}$ in a refrigerator ${ }^{[17,18]}$ For preparing pre-culture, 1.3 loopful of cells from a 24-h actively growing culture on a nutrient agar plate was transferred into a $20 \mathrm{ml}$ bottles containing freshly nutrient broth (NB) $10 \%\left(\mathrm{w} \mathrm{v}^{-1}\right)$ and then it was incubated at $37^{\circ} \mathrm{C}$ in a microbiological incubator (M Emmert-Germany/BE 600 ) at $37{ }^{\circ} \mathrm{C}$ for 24 hours at a vigorous shaking of $180 \mathrm{rpm}$ using Orbital Shaker (B. Braun, German model). After 24 hours, the inoculum was transferred into a $500 \mathrm{ml}$ Erlenmeyer flask containing $150 \mathrm{ml}$ of nutrient broth $\left(\mathrm{wv}^{1-}\right)$ with $30 \%\left(\mathrm{vv}^{-1}\right)$ of the original volume of the shake flask ${ }^{[19]}$. The inoculation process was aseptically performed inside a laminar flow to avoid any contamination; as well the flask was passed over a Bunsen burner flame before seeding and after. This inoculation was done three times each to ensure proper bacterial growth. The samples were then placed on a shaker and calibrated for agitation and temperature accordingly for each run. The experiment was run under the selected different ranges of nutrient concentration, acclimatization time, agitation, and temperature for 24 and 72 hours each. The medium $\mathrm{pH}$ was kept constant at a near neutral of $7.0 \pm 2$ throughout the experiment using $0.5 \mathrm{M}$ buffer, hence is not mentioned as a factor. The effect of these factors on the growth of $B$. cereus was monitored and analyzed.

\subsection{Analytical Procedure}

For growth analysis, $2.5 \mathrm{ml}$ aliquots were withdrawn periodically at fixed intervals for 24 hours. Growth was monitored turbidimetrically by measuring optical density (absorbance) of samples periodically withdrawn aseptically from the flasks. Absorbance was estimated at wavelength $600 \mathrm{~nm}$ against a blank NB using UV-VIS Spectrophotometer (Hitachi, U-1800, Japan), after appropriate dilution to obtain an OD value of $<0.5$ in ${ }^{[20]}$ modified. This is to ensure that the Beer-Lambert law applies. Alternatively, a range could also be selected when a huge growth is expected so as to remain within the linear part of the relation between cell number and optical density 
without any need for a dilution to get a reliable value (Galushko, 2015). Optical density is an indirect method for measuring bacterial growth which is based on the mechanism of light passing through a suspending medium. This concept is based on the fact that, as the cells grow the suspension become more turbid, hence the less percentage of light transmitted. However, UV-VIS spectrophotometer is working based on absorbance of light by the suspended medium, which is directly proportional to the increase in cell number and inversely proportional to percentage light transmission (\% T).

\subsection{Factorial Design for Screening Main Parameters Affecting Bacterial Cell Growth}

In this study, four factors e.g. nutrient concentration, temperature, acclimatization time and agitation speed were selected and screened for their effect on cell growth of $B$. cereus (measured at OD 600nm) using a fractional two $\left(2^{4}\right)$ level factorial design. These factors were selected based on the information from scientific articles. The levels of independent variables; nutrient concentration, temperature, acclimatization time and agitation speed, were based on the results obtained in previous OFAT studies by Azoddein, et al., ${ }^{[20]}$. Each variable or factor was studied at two coded level; low-level (-1) and high-level (+1). Table $1 \& 2$ show a designed matrix of the factors and levels employed for the experiment and a total of eight runs $\left(2^{3}\right)$ were conducted in replicated to minimize presumed experimental and other errors. The effect of each variable and their interactions on the cell growth was statistically determined. True response surface was approximated over a small experimental region by a low-order polynomial. A first-order polynomial model is only able to estimate the main effects of the experimental factors and does not account for either interactions or curvilinear effects. If there is little curvature in the limited region, a first-order model with interaction is appropriate for modeling. Adding interaction terms introduces curvature into the response function ${ }^{[15]}$. The first-order model with interaction terms proposed for each response variable (Yi) was based on the multiple linear regression methods. A probability $(\mathrm{P})$ value for a given factor less than 0.05 (95\% confidence interval) was considered as significant. For three factors system a polynomial equation model in terms of coded factors was used to predict the response of bacterial cells to the selected variables:

$\mathrm{Y}=\beta_{0}+\beta_{1} \mathrm{X}_{1}+\beta_{2} \mathrm{X}_{2}+\beta_{3} \mathrm{x}_{3}+\beta_{12} \mathrm{X}_{1} \mathrm{X}_{2}+\beta_{13} \mathrm{X}_{1} \mathrm{x}_{3}+\beta_{23} \mathrm{X}_{2} \mathrm{X}_{3}$

Where $\beta_{i}$ are the values of the regression coefficients, $\beta_{0}$ being the constant term, $\beta_{1}, \beta_{2}$ and $\beta_{3}$ the linear effects, $\beta_{12}, \beta_{13}$ and $\beta_{23}$ the interaction effects while the $\mathrm{A}\left(\mathrm{x}_{1}\right), \mathrm{B}\left(\mathrm{x}_{2}\right)$, $\mathrm{C}\left(\mathrm{x}_{3}\right)$ are the independently coded variables (nutrient concentration, temperature difference, acclimation time and agitation respectively). Stepwise deletion of terms was applied to eliminate the statistically non-significant terms. The goodness of fit of the model and significance of each regression coefficient was evaluated by regression analysis of the residual values, analysis of variance (ANOVA) and by the correlation coefficient $\mathrm{R}^{2}$ parameters (Eq. 4-9). The statistical significance was checked by the F-test $[12,15]$. These statistical parameters used to validate the fitness of a particular model are given by the equations below:

$R^{2}=1-\left[\frac{S S_{\text {residual }}}{S S_{\text {residual }}+S S_{\text {model }}}\right]=1-\left[\frac{S S_{\text {residual }}}{S S_{\text {total }}-S S_{\text {eurvature }}-S S_{\text {block }}}\right]$

Adj. $\mathrm{R}^{2}=1-\left[\left(\frac{S S_{\text {residual }}}{d f_{\text {residual }}}\right) /\left(\frac{S S_{\text {residual }}+S S_{\text {modal }}}{d f_{\text {residual }} d f_{\text {modkl }}}\right)\right]=1-\left[\left(\frac{S S_{\text {residual }}}{d f_{\text {residual }}}\right) /\left(\frac{S S_{\text {rotal }}-S S_{\text {curvaturg }}-S S_{\text {block }}}{d f_{\text {total }}-d f_{\text {curvaturg }}-d f_{\text {block }}}\right)\right]$

Pred. $R^{2}=1-\left[\frac{\text { PRESS }}{S S_{\text {residual }+S S_{\text {model }}}}\right]=1-\left[\frac{\text { PRESS }}{S S_{\text {total-SS }}}\right]$ 
Adequate Precision: $\left[\frac{\max (\hat{\gamma})-\min (\hat{\gamma})}{\sqrt{v} \hat{\gamma}}\right]>4 \quad \bar{v}(\hat{\gamma})=\frac{1}{n} \sum_{i=1}^{n} v(\hat{\gamma})=\frac{p \sigma^{n}}{n}$

Where the $\mathrm{P}=$ number of model parameters (including intercept $\left(b_{0}\right)$ and any block coefficients), $\sigma^{2}=$ residual MS from ANOVA table $n=$ number of experiments.

$$
\text { PRESS }=\sum_{i=1}^{n}\left(e_{i_{i}-i}\right)^{2}=\sum_{i=1}^{n}\left(\frac{\epsilon_{i}}{1-h_{i i}}\right)^{2}
$$

On the other hand statistical model to identify those factors that had a significant effect, either positively or negatively on the dependent variable (bacterial growth) is a need. The impact of each parameter was evaluated as the difference between the average value of the response for the eight experiments at the absolute high level $(+1)$ and the low level (-1) by below equation:

$$
E\left(X_{i}\right)=\sum \frac{\operatorname{Rat}(+1)}{n(+1)}-\sum \frac{\operatorname{Rat}(-1)}{n(-1)}
$$

Where $\mathrm{E}(\mathrm{Xi})$ is the main effect of the measured variable, $\mathrm{R}$ is the response, $n$, a number of an experimental run for a particular level (+ or -). It was indicated that, when the variable sign is positive, then their effect on bacterial growth is significant at higher value or concentration, while the effect of the variable is greater at low concentration when the sign is negative [16].

\section{Table 1. Actual Values of Experimental Variables use in the $2^{3}$ Fractional Factorial Design}

\begin{tabular}{llcc}
\hline \multirow{2}{*}{ Variables } & \multicolumn{3}{c}{ Range } \\
\cline { 2 - 4 } & Units & Low $(-\mathbf{1})$ & High (+1) \\
\hline Nutrient Concentration $\left(\mathrm{A} / \mathrm{x}_{1}\right)$ & $\mathrm{g} / \mathrm{l}$ & 4 & 16 \\
Temperature $\left(\mathrm{B} / \mathrm{x}_{2}\right)$ & ${ }^{\mathrm{O}}$ & 30 & 42 \\
Acclimatization time $\left(\mathrm{C} / \mathrm{x}_{3}\right)$ & hours & 24 & 72 \\
Agitation speed $\left(\mathrm{D} / \mathrm{x}_{4}\right)$ & $\mathrm{rpm}$ & 140 & 200 \\
\hline
\end{tabular}

\begin{tabular}{|c|c|c|c|c|c|}
\hline \multirow[b]{2}{*}{ Run } & \multicolumn{4}{|c|}{ Factors } & \multirow{2}{*}{$\begin{array}{c}\text { Response } \\
\text { Growth (Average } \\
\text { OD 600nm) }\end{array}$} \\
\hline & $\begin{array}{c}\text { Coded/uncoded } \\
\qquad\left(\mathbf{x}_{1}\right)\end{array}$ & $\begin{array}{l}\text { Coded/uncoded } \\
\qquad\left(\mathbf{x}_{2}\right)\end{array}$ & $\begin{array}{c}\text { Coded/uncoded } \\
\left(\mathbf{x}_{3}\right)\end{array}$ & $\begin{array}{l}\text { Coded/uncoded } \\
\left(\mathbf{x}_{4}\right)\end{array}$ & \\
\hline 1 & $+1(16)$ & $-1(30)$ & $+1(72)$ & $-1(140)$ & $1.958 \pm 0.022$ \\
\hline 2 & $+1(16)$ & $+1(42)$ & $+1(72)$ & $+1(200)$ & $3.000 \pm 0.019$ \\
\hline 3 & $-1(4)$ & $-1(30)$ & $+1(72)$ & $+1(200)$ & $1.644 \pm 0.032$ \\
\hline 4 & $-1(4)$ & $+1(42)$ & $-1(24)$ & $1(200)$ & $0.901 \pm 0.017$ \\
\hline 5 & $+1(16)$ & $-1(30)$ & $-1(24)$ & $+1(200)$ & $2.000 \pm 0.023$ \\
\hline 6 & $-1(4)$ & $+1(42)$ & $+1(72)$ & $-1(140)$ & $1.376 \pm 0.016$ \\
\hline 7 & $+1(16)$ & $+1(42)$ & $-1(24)$ & $-1(140)$ & $3.000 \pm 0.021$ \\
\hline 8 & $-1(4)$ & $-1(30)$ & $-1(24)$ & $-1(140)$ & $1.325 \pm 0.040$ \\
\hline
\end{tabular}

Table 2. $2^{3}$ Fractional Factorial Design Coded Levels Matrix 


\section{Results and Discussion}

\subsection{Screening of Variables for B. cereus Growth using Fractional Factorial Design (FFD)}

Four variables were assessed at different level regarding their effect on bacterial growth using fractional factorial design. The design matrix selected for the screening of significant factors on the growth and their corresponding responses were indicated in Table 1. From the responses, the mean value of cells growth was 1.90 OD With a standard deviation of 0.057 . Based on the results, however, it can be inferred that the linear and interactions impact or otherwise for the screened variables to bacterial growth was quite correlating. The independent and dependent variables were found to have fitted to the first-order polynomial model equation with interaction terms and for each response, the variable was examined for the goodness of fit. Table 3 presented the overall diagnostic statistical report for the experimental runs. Figures from this table indicated the specific linear and somehow the interactions contribution of the independent variables to bacterial growth. This can be seen from the non-synergistic figures of actual versus predicted mean values, as well as the large influence of fitted values and cook's distance. This anomaly was also quite clear from the design matrix results in runs 3, 4, 6 and 8 (Table 2). But the reason for this disparity on the model terms remains unknown, although it may be apportioned to design or data error. Table 4, 5 and 6 presented the screened results via student's t-test for ANOVA with the regression relationships for each response monitored. The results show the value P-model in the ANOVA was lower 0.05, which indicated a significant relationship between the variables at $95 \%$ confidence level (Table 4). The model depicted high determination coefficient $(\mathrm{R}$ - Squared $=0.9984)$, which explain $99.84 \%$ of the variability in bacterial growth (Table 5). According to some previous findings, model terms of $P$ value less than 0.05 implies that model term is significant ${ }^{[12,14,16,22-26]}$. The $P$ values were used as a tool to check the significance of each of the coefficients, which in turn may indicate the pattern of the interactions between the variables. The smaller the value of $P$, the more significant was the corresponding coefficient ${ }^{[27]}$.

Cell growth $=1.90+0.59 \mathrm{~A}+0.17 \mathrm{~B}+0.094 \mathrm{C}+0.34 \mathrm{AB}-0.10 \mathrm{AC}$

Table 3. Diagnostic Case Statistics Report for Screening Experimental Run

\begin{tabular}{|c|c|c|c|c|c|c|c|c|c|}
\hline $\begin{array}{c}\text { Std } \\
\text { Order }\end{array}$ & $\begin{array}{c}\text { Actual } \\
\text { Value }\end{array}$ & $\begin{array}{c}\text { Pred. } \\
\text { Value }\end{array}$ & Residual & Leverage & $\begin{array}{c}\text { Internally } \\
\text { Studentized } \\
\text { Residual }\end{array}$ & $\begin{array}{c}\text { Externally } \\
\text { Studentized } \\
\text { Residual }\end{array}$ & $\begin{array}{c}\text { Influence on } \\
\text { Fitted Value } \\
\text { DFFITS }\end{array}$ & $\begin{array}{c}\text { Cook's } \\
\text { Distance }\end{array}$ & $\begin{array}{c}\text { Run } \\
\text { Order }\end{array}$ \\
\hline 1 & 1.33 & 1.29 & 0.039 & 0.750 & 1.366 & 3.714 & $* \mathbf{6 . 4 3}$ & $\mathbf{0 . 9 3 2}$ & 8 \\
\hline 2 & 2.00 & 1.99 & 0.010 & 0.750 & 0.368 & 0.269 & 0.466 & 0.068 & 5 \\
\hline 3 & 0.90 & 0.94 & -0.039 & 0.750 & -1.366 & -3.714 & $*-\mathbf{6 . 4 3}$ & $\mathbf{0 . 9 3 2}$ & 4 \\
\hline 4 & 3.00 & 3.01 & -0.011 & 0.750 & -0.368 & -0.269 & -0.466 & 0.068 & 7 \\
\hline 5 & 1.64 & 1.68 & -0.039 & 0.750 & -1.366 & -3.714 & $*-\mathbf{6 . 4 3}$ & $\mathbf{0 . 9 3 2}$ & 3 \\
\hline 6 & 1.96 & 1.97 & -0.011 & 0.750 & -0.368 & -0.269 & -0.466 & 0.068 & 1 \\
\hline 7 & 1.38 & 1.34 & 0.039 & 0.750 & 1.366 & 3.714 & $* \mathbf{6 . 4 3}$ & $\mathbf{0 . 9 3 2}$ & 6 \\
\hline 8 & 3.00 & 2.99 & 0.010 & 0.750 & 0.368 & 0.269 & 0.466 & 0.068 & 2 \\
\hline
\end{tabular}


Table 4. ANOVA Table for the Growth Response

\begin{tabular}{lllllll}
\hline Source & df & Adj. SS & Adj. MS & F-Value & p-Value & \% Contribution \\
\hline Model & 5 & 4.09558 & 0.81912 & 251.07 & 0.004 & --- \\
Linear & 3 & 3.07387 & 1.02462 & 314.06 & 0.003 & -- \\
Nutrient & 1 & 2.77537 & 2.77537 & 850.69 & 0.001 & 67.66 \\
Temperature & 1 & 0.22781 & 0.22781 & 69.83 & 0.014 & 5.55 \\
Acclimatization & 1 & 0.07069 & 0.07069 & 21.67 & 0.043 & 1.72 \\
Interactions & 2 & 1.02171 & 0.51085 & 156.58 & 0.006 & --- \\
Nutrient versus Temp. & 1 & 0.93434 & 0.93434 & 286.39 & 0.003 & 22.78 \\
Nutrient versus Acclim & 1 & 0.08736 & 0.08736 & 26.78 & 0.035 & 2.13 \\
Residual Error & 2 & 0.00653 & 0.00326 & & & \\
Total & 7 & 4.1021 & & & & \\
\hline
\end{tabular}

Table 5. Statistics used to Test Goodness of Fit of the Models

\begin{tabular}{lc}
\hline Parameters & Values \\
\hline R-Squared & $0.9984(99.84 \%)$ \\
Adj R-Squared & $0.9944(99.44 \%)$ \\
Pred. R-Squared & $0.9745(97.45 \%)$ \\
Adeq. Precision & 41.857 \\
Std. Dev & 0.057 \\
Mean & 1.90 \\
Coefficient of Variability (C.V.) & 3.01 \\
PRESS & 0.10 \\
\hline
\end{tabular}

\section{2 Main Variable Effects Analysis on the Dependent Variable}

Table 6 shows the explicative linear effect of variables which can be estimated from their sign (+ or -$)$ and their magnitude. These Positive and negative signs indicate increasing or decreasing impact of each variable on bacterial growth. There are three potential variables (nutrient concentration, temperature and acclimatization time), which have a positive sign and other last variables (agitation speed) had a negative sign. All the model terms were significant at $\mathrm{p}<0.05$. The model term having the most significant effect on the growth response is A with $F$-value of 850.69 and $p=0.001$ (i.e. $p<0.05$ ) and the effect is in the ascending order $\mathrm{A}>\mathrm{B}>A B>\mathrm{AC}>C$. Table 4 indicated the statistical analysis of variance (ANOVA) of the experimental factors and their percentage contribution, coupled with their interaction effects to bacterial growth. Figure 1 shows the trend of main effects plots when the factors are varied in their positive and negative level. For the overall individual eff ect, these graphs show that factor A- and B- have a least significant effect on the cell growth compared to $\mathrm{A}+,, \mathrm{B}+, \mathrm{C}$ - and $\mathrm{C}+$, while factor $\mathrm{D}$ seemed not significant, although a little more responding at negative level. The factors with steeper slopes demonstrated the major eff ects, and thus, it would contribute to the largest impact on the experimental results. Therefore, the eff ect of factor A, nutrient concentration, was identified as the largest contributor compared to other factor eff ects. 
Comparatively, Figure 2 as well depicted the main individual effect of signals on the dependent variable. Perturbation plot does not show interactions effect, thus it is like a one-factor-at-a-time experimentation. However, it can be utilize in comparing the effects of factors by default in their corresponding centre levels in the design space. The response is plotted by changing only one factor over its range while holding of the other factors constant. A steep slope or curvature in a variable indicates that the response is sensitive to that factor.

A relatively flat line shows insensitivity to change in that particular factor ${ }^{[24]}$. It's quite clear that the impact of nutrient concentration was responded much at a higher concentration (positive deviation) point over all the other factors. Temperature and acclimatization time on the other hand were less steep and contribute to the growth at lower range or negative deviation point from the center. Overall, a main and interactions effect of the variables was depicted in Figure 2. It has been shown that the bar lengths of Pareto chart are proportional to the absolute value of the estimated effects at $95 \%$ confidence level, which indicate order of significance of each linear and interactions effects of the variables, with nutrient concentration demonstrated the most significant effect on the growth of $B$. cereus. The interaction of nutrient concentration and temperature difference effects were very small in comparison with linear effects but it was also significant at $95 \%$ confidence level. This pattern agrees well with what was reported by Onsekizoglu, et al., ${ }^{[15]}$.

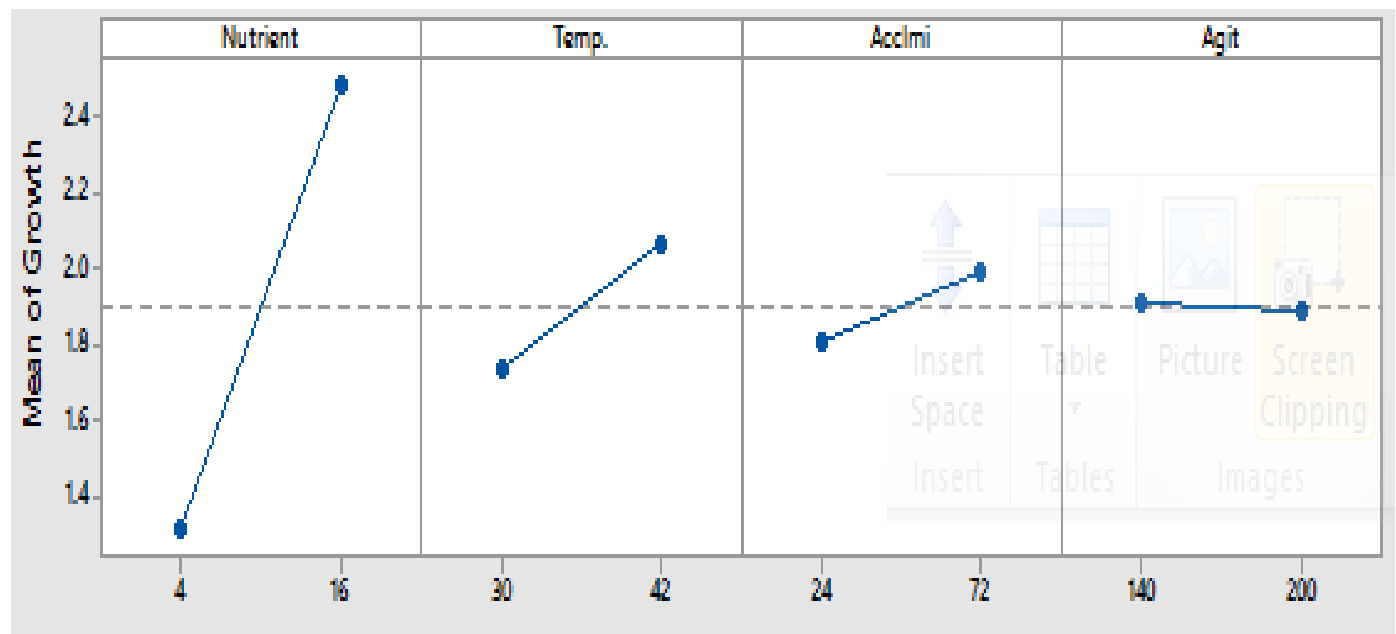

Figure 1. Main Effects Plot for the Screening of Growth Markers using FFD 


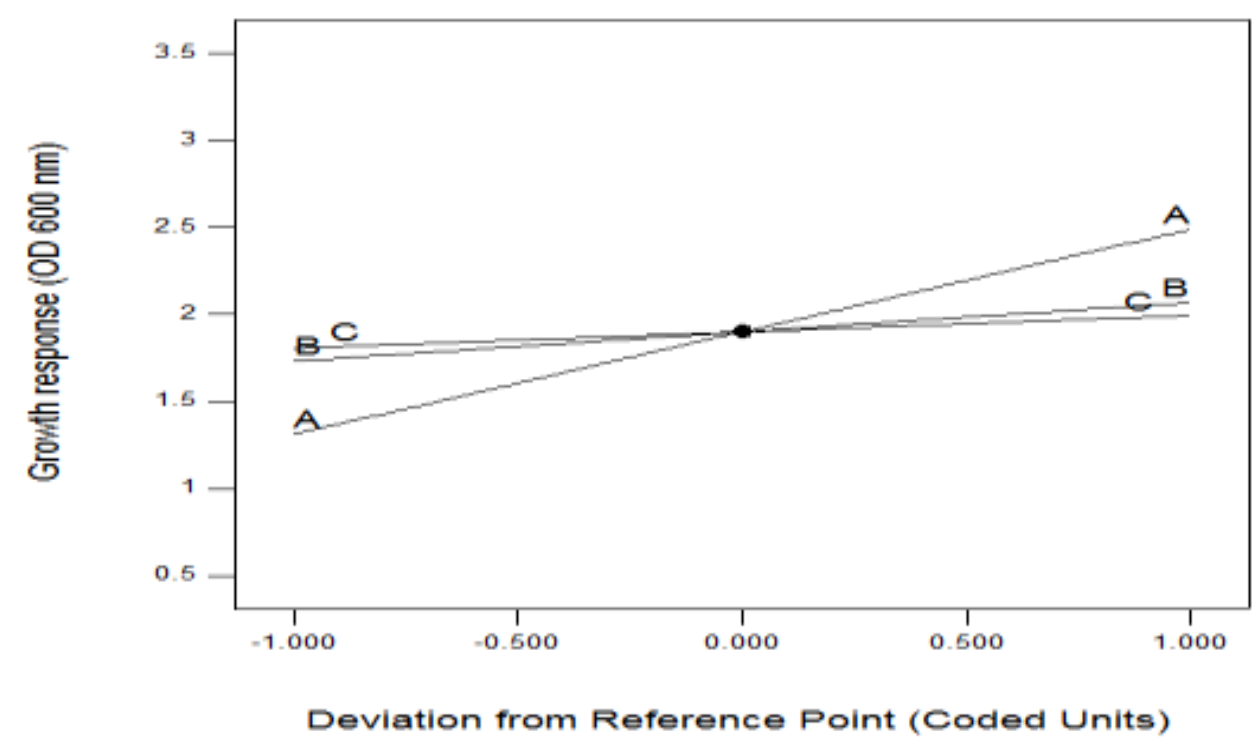

Figure 2. Perturbation Plot of Main Signals Effects on P. putida Growth

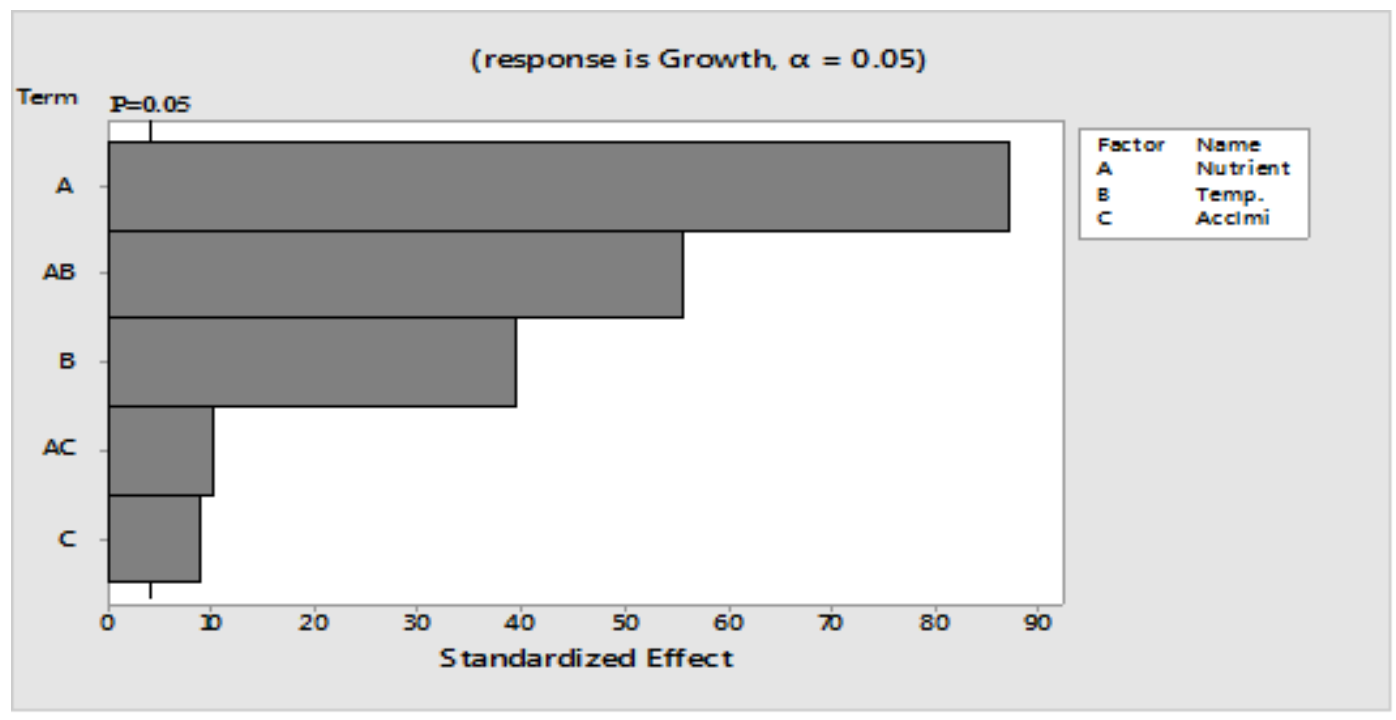

Figure 3. Pareto Chart of Factors' Main and Interactive Effects

\subsubsection{Effect of Nutrient Concentration}

The nutrient concentration with the highest percentage contribution of $67.66 \%$, mean tvalue of 29.17 and main effect of 1.18 was obtained from the analyzed results. It was observed to be the main and most important factor affecting $B$. cereus growth. Nutrient being the main constituent of cell biomass is required for bacterial growth and biosynthesis under optimum physical parameters of main temperature, the age of the culture and acclimatization time. For microbes, growth is their most essential response to their physiochemical environment [28]. Bacterial growth and biomass response to media were found to rely heavily on different composition ranging from single to multiple substrates, although screening and optimization approach of medium constituents is not much popular [3]. Although the nutrient concentrations used in this work were inside the range of values normally used for $B$. cereus culture media, the cell density was 
significantly higher at a range greater than the recommended value [29, 30]. In addition, the growth rate is observed to be a function of nutrient composition [31], uptake and utilization which is also a function of growth machinery or phase.

Table 6. Statistical Analysis of the Explicative Factors on B. cereus Growth via Fractional Factorial Design (FFD)

\begin{tabular}{llllll}
\hline Variables & Terms & $\begin{array}{l}\text { Main } \\
\text { Effect }\end{array}$ & t-Value & $\begin{array}{l}\text { p- } \\
\text { Value }\end{array}$ & $\begin{array}{l}\text { Confidence Level } \\
(\%)\end{array}$ \\
\hline A & Nutrient Conc. & 1.18 & 29.17 & 0.001 & $99.90 \%$ \\
B & Temperature & 0.34 & 8.29 & 0.014 & $98.60 \%$ \\
& $\begin{array}{l}\text { Acclimatization } \\
\text { time }\end{array}$ & 0.19 & 4.65 & 0.043 & $95.70 \%$ \\
D & Agitation & -0.03 & 0.58 & 0.667 & $33.30 \%$ \\
\hline
\end{tabular}

\subsection{Effect of Temperature}

The operational and invariably environmental temperature range was the second most contributing variable to B. cereus growth. Although this strain is mesophilic in nature as well as spore-forming type, it was observed to thrive better at a temperature range of 36$40^{\circ} \mathrm{C}$. Percentage contribution of this variable was no more than a tenth that of nutrient contribution. Substrate utilization for bacterial growth and biomass synthesis is indeed enzyme dependent mechanism which rests so much on the temperature. Enzymatic activities are reported to be very aggressive up to a certain temperature threshold from where it cast a negative effect of denaturing the enzyme, thus decelerating the growth possibly due to slowed metabolism. In addition temperature range of $36-40^{\circ} \mathrm{C}$ speed up the rate of substrate uptake and utilization and subsequent incorporation form cell biomass synthesis. A similar trend of bacterial growth was reported by ${ }^{[20]}$. This temperature range is closer to that of the surrounding environment especially in a tropical climate type of Malaysia as well more economical due to less energy required.

\subsubsection{Effect of Acclimatization Time}

Acclimatization time or residence time is the least important variable with a percentage contribution of $1.7 \%$. It is an important indicator by the way especially as it related to the age of the inoculated culture which requires a longer time to acclimatize to its new medium as indicated by a little longer lag phase. Upon introduction into the new environment, B. cereus is able to organize its cellular constituents and require no more than 24hours to reach a peak exponential growth phase. However other factors may prolong this period to least 36-48 hours depending on the age of the culture, species and nutrient composition and type. Acclimatization time effect on growth was reported by ${ }^{[32]}$, although with a little longer time of 72 hours, while Azoddein, et al., ${ }^{[20]}$ reported similar time period bacterial growth and biomass synthesis.

\subsection{Interactions Effects of the Variables on the Growth}

This is the most important component of screening the variables effects by identifying how their individual effect interacts with each other to impact the dependent variable positively. Figure 4 (a \& b) show the interactions (two-way interactions eff ects, 2FI) of the significant factors above $0.5 \%$ (95\%) significant level. Figure 4a shows the interaction of nutrient concentration and temperature difference (AB), which was statistically significant with F-value of 286.39. This is the most important independent variables interactions effect on the $B$. cereus growth, second to the main effect of nutrient 
concentration in term of contribution. This interaction is larger at a nutrient concentration of $15 \mathrm{~g} / \mathrm{l}$ and temperature of $40^{\circ} \mathrm{C}$ and a fixed acclimatization time of 48 hours with a resultant optimal cell density of $\geq 3 \mathrm{OD}$. The steeper the contour plot the more significant the interaction effect on the dependent variable. It is indicated that at an optimum temperature range, enzyme activities is enhanced which speed up the rate of nutrient utilization and thus subsequent higher cell biomass synthesis. The results were in agreement with the previous findings ${ }^{[27,33]}$. The sustainability of this isolate at such a high-temperature range was probably due to the spore- forming nature. Figure $4 \mathrm{~b}$, on the other hand, shows the interaction effects of nutrient and acclimatization time (AC) which was found to be of less impact to bacterial growth. This was clearly indicated by the somehow parallel contour plot which shows time to be less significant in term of nutrient utilization. However, a growth of not more than 2.5 OD600 nm was recorded at a hold temperature value of $40^{\circ} \mathrm{C}$. Although growth appeared to be insensitive to time, it was, however effective at high nutrient concentration, with some degree of variation at a low nutrient range between 24 and 72 hour acclimatization time.

(a)
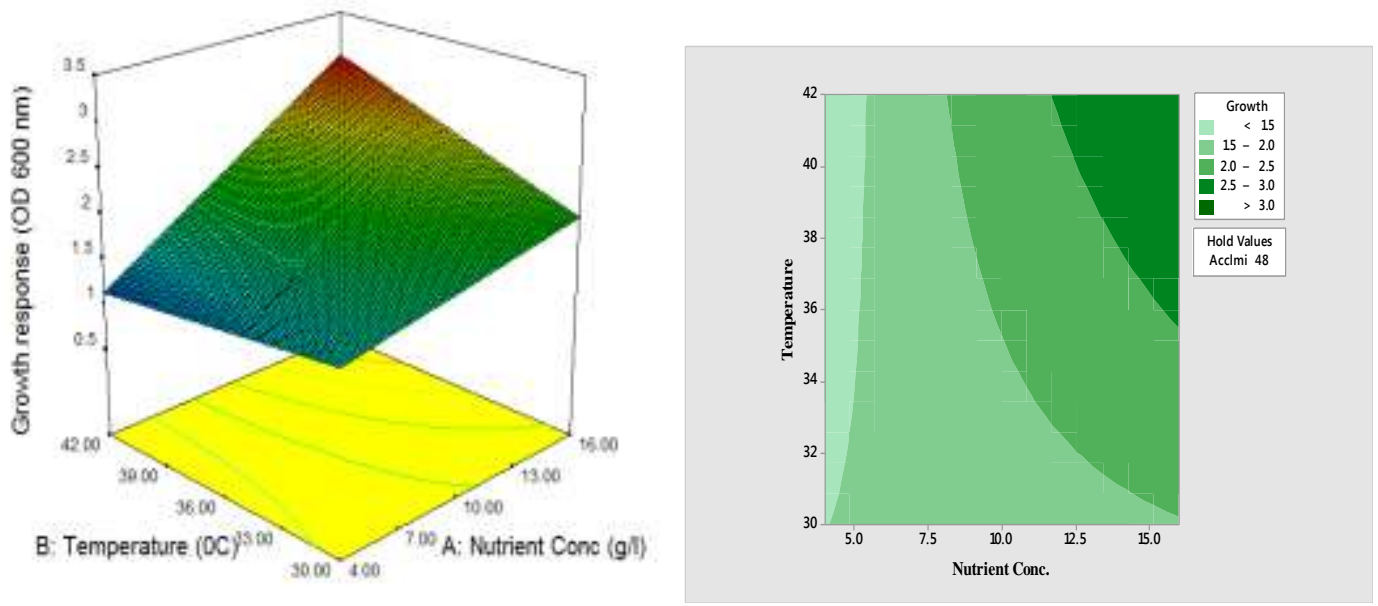

(b)
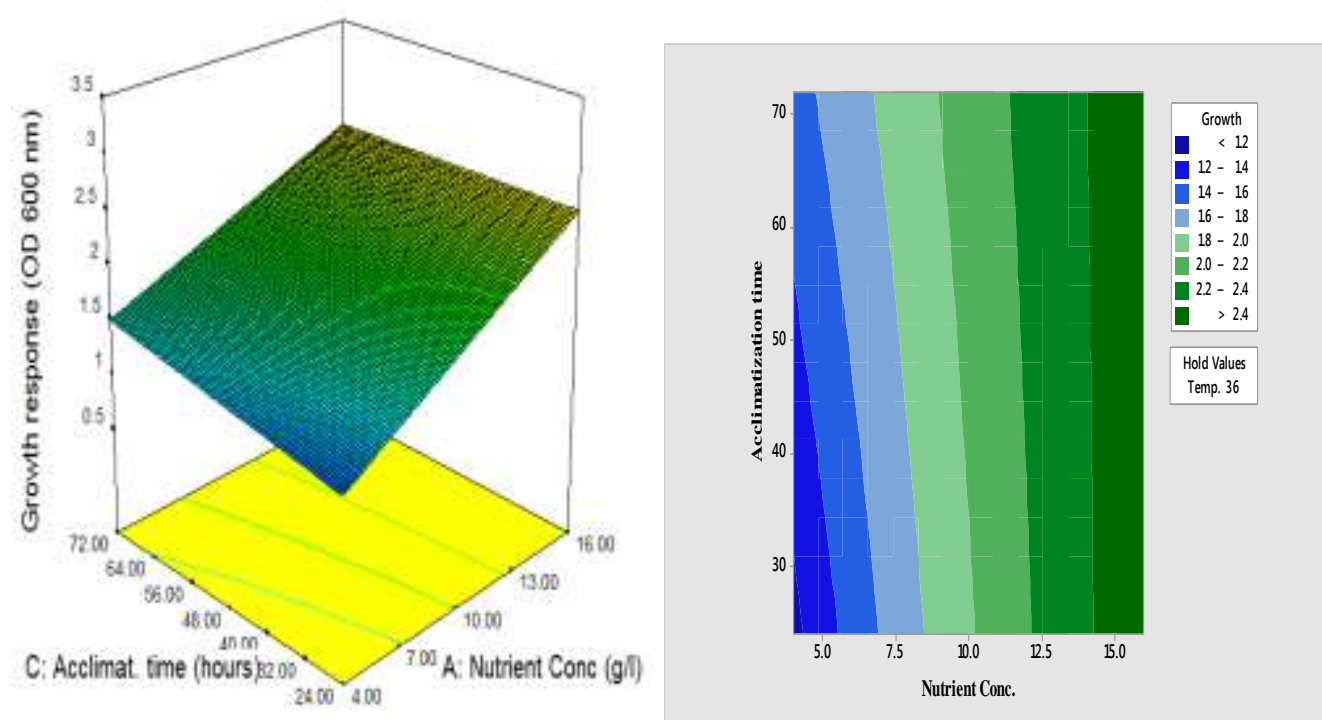

Figure 4. Screening of Interactive Surface Plots: (a) Contour plots (b) Surface Plots: (a) Nutrient Concentration (A) and Temperature (B) at Fixed Acclimation Time $C=48 \mathrm{hr}$ and Agitation Speed $D=188.65$ (b) Nutrient Concentration (A) and Acclimation Time (C) at a Fixed Temperature $(B)=36$ and Agitation Speed $(C)=188.65$ 


\subsection{Validity of the Model}

The goodness of fit of the model was evaluated by the coefficient of determination $\left(\mathrm{R}^{2}\right)$, adjusted- $\mathrm{R}^{2}$, predicted- $\mathrm{R}^{2}$, coefficient of variance $(\mathrm{CV})$, the prediction residual error sum of squares (PRESS), adequate precision and the lack of a fit test for the model from the ANOVA table. Tables 4 and 5 summarize the statistics used to test the adequacy of the model. The p-value for the model was less than 0.05 , hence indicating that the terms in the model have significant effects on the response. The coefficient of determination $\left(\mathrm{R}^{2}\right)$ is the proportion of variation in the response (s) attributed to the model. It is suggested that $\mathrm{R}^{2}$ should be close to 1 for a good fit model (i. e. not less than 0.8 for biological processes). The estimated model for growth had satisfactory $\mathrm{R}^{2}$ values of more than $90 \%$ variability in bacterial growth; however, it was argued that a large value of $\mathrm{R}^{2}$ does not always imply that the regression model is a good one. Thus, it is preferred to adopt the adjusted- $\mathrm{R}^{2}$ for evaluation of model fitness, since it is adjusted for the number of terms in the model. The adjusted- $\mathrm{R}^{2}$ should be over $90 \%$ which spell a high degree of relationship between the observed and predicted values. Table 4 shows that $R^{2}$ and adjusted- $\mathrm{R}^{2}$ values for the models did not differ dramatically indicating non-significant terms have not been included in the model. Indeed, Table 4 indicates that all the fit indices indicated goodness of fit to the estimated model. The main and interaction effects of factors upon the responses are depicted in the three-dimensional surface plots (Figs. 5a and $5 \mathrm{~b}$ ). Figure $5 \mathrm{a}$ shows the combined effect of varying nutrient concentration and temperature at a defined acclimation time and agitation speed. Growth was observed to follow the normal curve between the temperature of $30^{\circ} \mathrm{C}$ to $36.6^{\circ} \mathrm{C}$ and up to $40^{\circ} \mathrm{C}$ reaching the peak growth of almost OD 3.0 from there it was noticed to start an abnormal trend. Utilization of nutrient for growth (biosynthesis), is an endergonic process, hence require an optimum temperature to function well, although higher temperature affects the enzymatic activity of this process which resulted in a declined growth pattern at extreme range. The results were in agreement with the previous findings ${ }^{[27,33]}$. However, the combined effect of nutrient concentration and acclimation time at a defined temperature and agitation speed was insignificant as indicated in Figure 5b.

The comparison plots of predicted versus the actual response values in Figures $4 \mathrm{a}$ and $4 \mathrm{~b}$, respectively, show a very minimal variance of points from the diagonal point out that the model equations can be used to adequately represent the interaction of the three factors. The value of predicted (3.01) and actual (3.0), which were depicted graphically by the distribution of the predicted values near to the straight reasonable agrees with the experimental data $\left(\mathrm{R}^{2}\right.$ 0.9984). Indeed, this further confirmed the very good prediction ability of the models. 


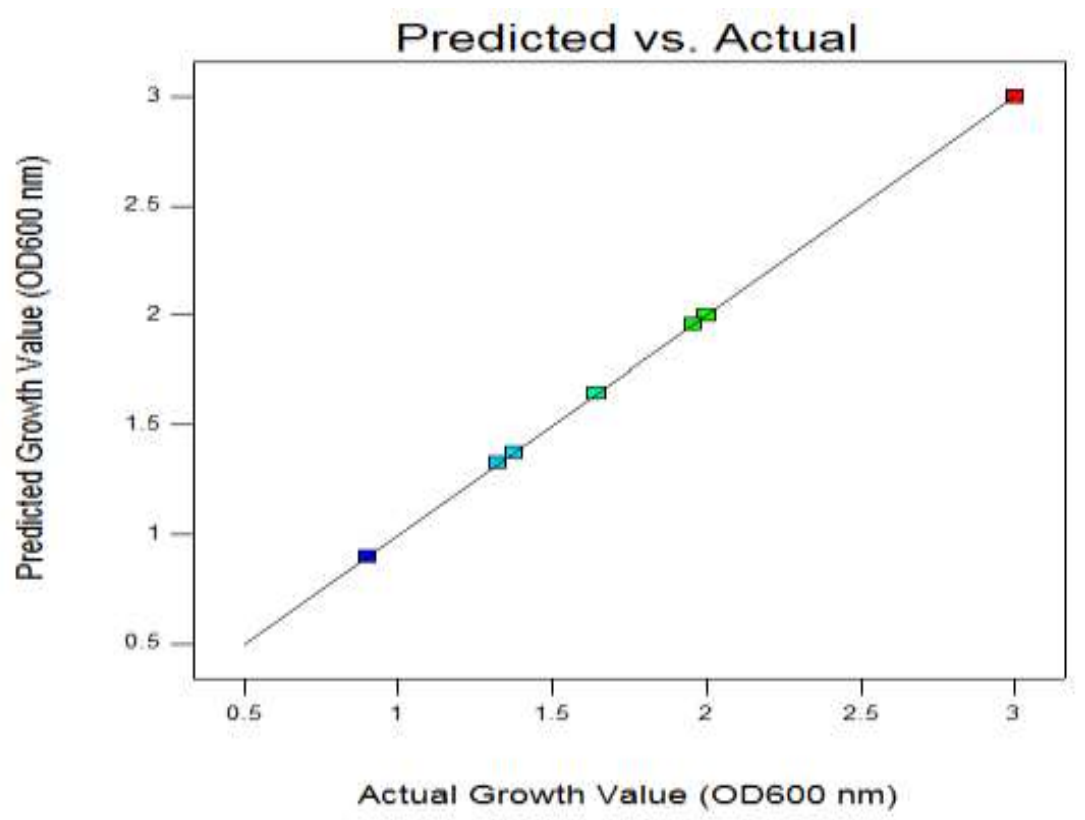

Figure 5. Predicted Value versus Actual Plots for B. cereus Growth

\section{Conclusion}

A two level $\left(2^{3}\right)$ factorial design with two center points was used for investigating the linear and interactions effects of varying nutrient concentration under different operational parameters of a shake flask. All the variables with the exception of agitation speed displayed a significant effect on isolate growth. The results indicated that nutrient concentration was more significant both in terms of linear and interaction effects on the response. Based on the adequacy testing tables; the estimated model terms spell high degree of relationship between observed and predicted values, thus further confirming the prediction ability of the models. In conclusion, the estimated model's terms could further be utilized to optimize the process conditions of this isolates' growth.

\section{Acknowledgement}

This research was funded through University Malaysia Pahang local research grant (RDU), with the technical support from the Faculty of Chemical and Natural Resources Engineering (FKKSA).

\section{Conflict of Interest}

The authors declare that they have no conflict of interest.

\section{References}

[1] Munna, M. S. et al. Influence of Aeration Speed on Bacterial Colony Forming Unit (CFU) Formation Capacity. Am. J. Microbiol. Res. 2, 47-51 (2014).

[2] Siti, M. Z., Nurhaslina, R. C., \& Ku, H. K. (2013). Influence of agitation, pH, and temperature on growth and decolorization of batik wastewater by bacteria Lactobacillus delbruckii. International Journal of Research and Reviews in Applied Sciences, 14(2), 269-275.

[3] Mosquera, S., González-Jaramillo, L. M., Orduz, S. \& Villegas-Escobar, V. Multiple response optimizations of Bacillus subtilis EA-CB0015 culture and identification of antifungal metabolites. Biocatal. Agric. Biotechnol. 3, 378-385 (2014).

[4] Dos Santos, L. F. et al. Characterization and optimization of levan production by Bacillus subtilis NATTO. Rom. Biotechnol. Lett. 18, 8413-8422 (2013).

[5] Zhong, J. et al. Optimization of Bacillus subtilis cell growth affecting jiean-peptide production in fedbatch fermentation using central composite design. Electron. J. Biotechnol. 17, 132-136 (2014). 
[6] Swain, M. R., Kar, S., Padmaja, G. \& Ray, R. C. Partial characterization and optimization of production of extracellular alpha-amylase from Bacillus subtilis isolated from culturable cow dung microflora. Pol. J. Microbiol. 55, 289-96 (2006).

[7] Abada, E. A. Production Optimization of extracellular amidase enzyme by newly isolated Pseudomonas putida AP-2 from agricultural soil. Rend. Lincei 25, 523-530 (2014).

[8] Singh, S. K., Singh, S. K., Tripathi, V. R., Khare, S. K. \& Garg, S. K. Comparative one-factor-at-a-time, response surface (statistical) and bench-scale bioreactor level optimization of thermoalkaline protease production from a psychrotrophic Pseudomonas putida SKG-1 isolate. Microb. Cell Fact. 10, 114 (2011).

[9] Navaneeth, S., Bhuvanesh, S., Bhaskar, V., P, V. K. \& Kandaswamy, S. K. J. Optimization of medium for the production of subtilisin from Bacillus subtilis MTCC 441. J. Microbiol. Biotechnol. 8, 6327-6331 (2009).

[10] Cook, L. K. N. Optimizing Culturing Conditions for Bacillus Subtilis. South African Avocado Grow. Assoc. Year. 54-58 (1996).

[11] Mandenius, C.-F. \& Brundin, A. REVIEW : BIOCATALYSTS AND BIOREACTOR DESIGN Optimization, Bioprocess Methodology, Using Design-of-experiments. Biotechnol Progr 24, 1191-1203 (2008).

[12] Olfa Tabbene, Imen Ben Slimene, Kais Djebali, Maria-Luisa Mangoni, M.-C. U. and F. L. Optimization of medium composition for the production of antimicrobial activity by Bacillus subtilis B38. Biotechnol. Prog. 25, 1267-1274 (2009).

[13] Cho, J.-H., Kim, Y.-B. \& Kim, E.-K. Optimization of culture media for Bacillus species by statistical experimental design methods. Korean J. Chem. Eng. 26, 754-759 (2009).

[14] Ridzuan, N., Adam, F. \& Yaacob, Z. Screening of factor influencing wax deposition using full factorial experimental design. Pet. Sci. Technol. 34, 84-90 (2016).

[15] Onsekizoglu, P., Bahceci, K. S., \& Acar, J. (2010). The use of factorial design for modeling membrane distillation. Journal of Membrane Science, 349, 225-230. http://doi.org/10.1016/j.memsci.2009.11.049

[16] Hooshyar Hosseini, Abbas Rezaee, S. R. \& 1). Statistical screening of hexavalent chromium biosorption by Sargassum. Iran. J. Heal. Saf. Environ. 1, 36-42 (2014).

[17] Rashedi H, Izadi A, Bidhendi ME, Rashedi H. Optimization of Operational Parameters in Rhamnolipid Production by Pseudomonas aeruginosa MM1011 in a Miniaturized Shaken Bioreactor. J Appl Biotechnol Reports. 2015;2(3):271-8.

[18] Wang SJ, Loh KC. Modeling the role of metabolic intermediates in the kinetics of phenol biodegradation. Enzyme Microb Technol. 1999;25(3-5):177-84

[19] Standbury, P.F., Whitaker, A. and Hall SJ (1984). P of FTOBH. The principle of Fermentation. 2nd ed. Standbury, P.F., Whitaker, A. and Hall, S. J. (1984). Principles of Fermentation Technology. Oxford: Butterworth Heinemann. OXFORD: BUTTERWORTH HEINEMANN; 1984.

[20] Roebuck, K., Brundin, A. \& Johns, M. Response surface optimization of temperature and pH for the growth of Pachysolen tannophilus. Enzyme Microb. Technol. 17, 75-78 (1995).

[21] Azoddein, A. A. M., Yunus, R. M., Sulaiman, N. M., Bustary, A. B. \& Sabar, K. Mercury Removal Using Pseudomonas putida ( ATTC 49128 ): Effect of Acclimatization Time, Speed, and Temperature of Incubator Shaker. Int. J. Biol. Biomol. Agric. Food Biotechnol. Eng. 9, 204-209 (2015).

[22] Mohammad, Y. S., Igboro, S. B., Giwa, A. \& Okuofu, C. A. Modeling and Optimization for Production of Rice Husk Activated Carbon and Adsorption of Phenol. Hindawi Publ. Corp. J. Eng. Volume 201, 110 (2014).

[23] Dutta, M., Ghosh, P. \& Basu, J. K. Statistical optimization for the prediction of ibuprofen adsorption capacity by using microwave assisted activated carbon. Appl. Sci. Res. 4, 1053-1060 (2012).

[24] Ramakrishna, G. \& Susmita, M. Application of response surface methodology for optimization of Cr ( III ) and Cr ( VI ) adsorption on commercial activated carbons. Res. J. Chem. Sci. 2, 40-48 (2012).

[25] Yahaya, N. K. E. M., Latiff, M. F. P. M., Abustan, I. \& Ahmad, M. A. Effect of preparation conditions of activated carbon prepared from rice husk by $\mathrm{ZnCl} 2$ activation for removal of $\mathrm{Cu}$ ( II ) from aqueous solution. Int. J. Eng. Technol. 10, 28-32 (2010).

[26] Siti Maryam Rusly, Shaliza Ibrahim, Rusly, S. M. \& Ibrahim, S. Adsorption of Textile Reactive Dye by Palm Shell Activated Carbon: Response Surface Methodology. World Acad. Sci. Eng. Technol. 43, 892895 (2010).

[27] Heo, S., Lee, H. \& Ha, S. A Predictive Model for the Growth Rate of Bacillus cereus in Broth by Response Surface Methodology. Biotechnol. Bioprocess Eng. 202-206 (2009). doi:10.1007/s12257-0080187-0

[28] Volesky, B. Biosorption and me. Water Res. 41, 4017-4029 (2007).

[29] Fu, G. et al. Characterization of a bacterial biocontrol strain B106 and its efficacies on controlling banana leaf spot and postharvest anthracnose diseases. Biol. Control 55, 1-10 (2010).

[30] Ye, Y. Feng et al. Identification of Antifungal Substance (Iturin A2) Produced by Bacillus subtilis B47 and Its Effect on Southern Corn Leaf Blight. J. Integr. Agric. 11, 90-99 (2012).

[31] Franklin, O., Hall, E. K., Kaiser, C., Battin, T. J. \& Richter, A. Optimization of biomass composition explains microbial growth-stoichiometry relationships. Am. Nat. 177, E29--42 (2011).

[32] Sumitha J and Sivakumar T. Optimisation of Medium and its Components for efficient Caffene Degradation by Brevibacterium. Int. J. Adv. Res. Eng. Appl. Sci. 4, 29-37 (2015). 
[33] Caroline, C., Philippe, S., Soumille, H., Nguyen-the, C. \& Schmitt, P. Effect of temperature on growth characteristics of Bacillus cereus TZ415. 1-6 (2000). doi:10.1016/S0168-1605(00)00197-5

\section{Authors}

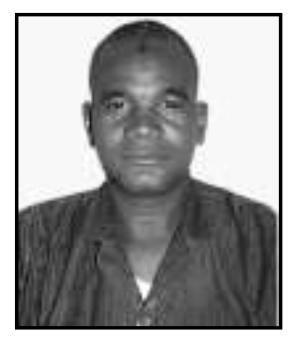

\section{Mani Malam Ahmad}

Faculty of Chemical and Natural Resources Engineering,

Universioty of Malaysia Pahang

26300, Gambang, Kuantan, Pahang 
International Journal of Bio-Science and Bio-Technology

Vol.9, No.3 (2017) 